\title{
Using an Accounting-based Management Control System for Cultural Change
}

\author{
James T. Mackey \\ California State University, Sacramento \\ Hugh D. Pforsich \\ California State University, Sacramento
}

Implementation of Continuous Improvement (CI) management has had a high failure rate (Jazayeri \& Hopper 1999). Cultural resistance (Irani et al. 2003) based on insufficient trust (Chenhall and LangfieldSmith 2003) is a key factor. When employment contracts fail, employees resist changes perceived to threaten their welfare. This paper uses an innovative action research approach to design and implement a Management Control System (MCS) that will reduce this problem. Supported by several theoretical bases, this research merges and applies an MCS with a Continuous Improvement Accounting Information System (CI-AIS) to an American factory.

\section{PREAMBLE}

An excellent explanation of action research is offered by Baskerville and Myers (2004). They suggest four premises that are most essential to action research. First, the theory must be established; Second, "there must be a practical action in the problem setting." Third, "the practical action must inform the theory." Fourth, and finally, the actions taken must involve the researchers and the participants in a social setting. All of these conditions are met in this paper.

Theoretical knowledge can only be validated through application. Innovation action research uses insights from theory to suggest an alternative solution in practice. The solution applied in this paper includes insights provided from information economics, agency theory, and constructivist learning theories. This combination of theoretical perspectives is necessary since no single theory is sufficient. A single theoretical perspective such as information economics or agency theory will not provide sufficient insights for implementation since each theory assumes away critical application issues (e.g., frictionless and instantaneous contracting) covered by the other theories (Covaleski et al. 2003).

Just as innovative action research has a documented role in the development and evolution of Activity-Based Costing and the Balanced Scorecard, it is a particularly useful approach for the implementation of theory in a CI context.

\section{INTRODUCTION}

The increasingly competitive global economy has prompted more and more businesses to adopt Continuous Improvement (CI) strategies. Some have enjoyed significant improvements in competitiveness and reduction in costs (Bohoris 1995; Corbett and Rastrick 2000; Najmi and Kehoe 
2000; Pool 2000; Prabhu et al. 2000; Terziovski and Samson 2000; Zairi and Whymark 2000a; Zairi and Whymark 2000b; Zairi et al. 1994; and Kahn 1998). These, however, are the exceptions. Unfortunately, CI implementation failures are all too common and results have been disappointing (McManus 1994; Martichenko 2004; Voss and Blackman 1996; Strebel 1996; Ezzamel et al. 1990; Ezzamel and Willmott 1998; Saravanamuthu 1998; Lewis 1996; Ngowi 2000; Maull et al. 2001; Calori and Sarnin 1991; Sinclair and Arthur 1994; Klein et al. 1995; and Corbett and Rastrick 2000).

World Class Management (WCM) programs, for example, designed to introduce a CI culture, typically take a minimum period of 15 to 18 months until the implementation is validated through accounting reports. Unfortunately, even with a liberal investment of resources, the reported impact on most companies has been unacceptably low (Westrup, Hopper, and Jazayeri 2001). Implementation failure often results when there is an overemphasis on tools and techniques (Corbett and Rastrick 2000) while transitioning to a business culture that is open to change ${ }^{3}$ is neglected (Page and Curry 2000).

Further, Quattrone and Hopper (2001), after investigating alternative approaches to SAP adoption, called for research in organizations where specific productivity expansion paths cannot be predicted in advance and where "control is no longer about prescribing 'right' courses of action but describing 'possible' courses of action." The model presented in this paper responds directly to these suggestions.

One of the primary factors responsible for CI implementation failures is cultural resistance (Samson 1997; Kotter and Heskett 1992). This paper introduces a MCS specifically designed to overcome cultural resistance and efficiently improve productivity. Resistance to new strategies can occur when employment contracts are not aligned with corporate strategies. One solution to such resistance is to provide more compensation to agents in order to match the level of risk that they bear. Alternatively, this paper suggests modifying the MCS in order to reduce agency risk and make contracting more efficient.

MCSs can assist in the formation and implementation of new management strategies (Simons 1995; Langfield-Smith 1997). They may use rule-based, standardized procedures within formal hierarchical structures, or they may use informal relationships characterized by cooperative personal interactions (Merchant 1985) as in a business culture. As employment contracts are designed by a company facing strategic change, flexible MCSs are most appropriate (Simons 1990; Chapman 1998). The preferred result is a cooperative approach to strategic change in a work environment of mutual trust. Where trust is sufficient, cultural change tends to proceed effectively. Where trust is insufficient, changes are likely to be resisted (Chenhall and Langfield-Smith 2003). The strategic design of the MCS can increase the level of trust among co-workers and facilitate their successful adaptation to change.

Since accounting profitability is a common normative value for most business cultures (Irani et al. 2003) accounting-based employment contracts are viable for both existing cultures and CI cultures. Consequently, accounting as the well-established dominant form of contracting (Sunder 2002) in business organizations should be considered when other methodologies fail (Lambert 2001).

Unfortunately, even when cultural change succeeds, financial improvement is not necessarily guaranteed. One Texas oil-drilling equipment company that was awarded the Malcolm Baldridge quality award from the U.S. Department of Commerce later sought Chapter 11 protection (Kaplan 1992). This indicates that even successful implementations may, in the extreme, become economic failures without sufficient accounting oversight. Thus, to improve implementation and reduce economic failure, the CIAIS must provide both cultural change and CI decision support.

First, this paper discusses the culture shift necessary for successful CI implementation. Then, previous research is used to design an adaptive MCS that will both enable, complement, and support the new CI culture (Adler and Borys 1996, Ahrens and Chapman 2004) and at the same time guide efficient CI productivity expansion learning models. Such an MCS is the focus of this paper.

In the next section, as background, the traditional control culture is described along with the commonly used accounting tools that support its preexisting employment contracting system (see Exhibit 1). Then, the primary characteristics of the CI culture are identified and the appropriate features of a complementary AIS that would foster the new culture's implementation and productivity expansion are suggested. 


\section{MANAGEMENT BY EXCEPTION AND STANDARD COSTING}

While few organizations operate at the extreme of a scientific management approach, this dominant paradigm significantly influences the design and operating conditions of most organizations to a greater or lesser extent. This discussion examines the conditions at the extremes which will provide insights into factors influencing performance without defining them in all specific conditions. Regardless of the degree of impact, the management of in-process costs in a CI culture is inconsistent with the traditional use of standard costs in budgeting systems.

Changing the culture and set of beliefs regarding the nature and objectives of control is required in order to introduce CI. Traditional management models in manufacturing settings emphasize Taylor's scientific method with its Management by Exception (MBE) practices (Taylor 1911). The scientific method is a "one best way" approach based on several assumptions:

1. The production technology is known,

2. The environment is both known and stationary,

3. Inputs are homogeneous, and

4. A single, understood goal is to be achieved (Jaikumar and Bohn 1992).

Under these conditions, experts are hired to design the "one best way" to produce a product. Management's objective is to insure that the "one best way" is implemented efficiently. This has led to a MBE approach to operational management forming part of the organization's culture within which employment contracting takes place. One example of MBE practices is to establish material and labor standards that define the most efficient way to complete processes. It is assumed that these standards represent the "one best way" that cannot be improved upon. Meeting the standards is part of the employment contract and sets the boundaries for management activities.

Standard costing systems have been used to assign costs to these standards and annual budgets are prepared to assist management in its planning and control functions. Standard costing and budgeting systems, based on these principles and the assumption that existing practices are nearly optimal, allow organizations to 1) contract efficiently based on accounting data, 2) reduce uncertainty in the coordination and communication of activities, 3) allocate resources, and 4) focus problem-solving efforts on exceptions, or variances, from the established standards.

Structured responsibility center accounting systems of this type create the boundaries for rational decision making. Contracting based on accounting data determines the limitations required for analyzing operating decisions. The accounting information that results from such decisions then becomes the normative criteria for the business culture, oftentimes referred to as "how we do things around here." However, how and where to best design technological process improvements is debatable. One view is that this should occur "off-line" in a controlled environment before implementation. Another approach assumes that only the in-process "laboratory of the shop floor" is efficient (Leonard-Barton 1992). This paper is limited to examining the latter process: in-process CI activities.

\section{CONTROL CULTURE: EFFICIENT PRODUCTIVITY CHANGE}

When an accounting system is closely aligned with an organization's business strategies, an efficient basis for employment contracting can be established. Over a period of time, the scientific method of management produces, reinforces, and, its critics would say, coerces an efficient culture of control which assumes that few improvements should be made during the operating period. The components of this control culture in a manufacturing environment typically include:

1. Engineered factory production lines with "practical standards," that are accepted as the "one best way" to operate,

2. Specialized responsibility centers coordinated through production schedules to manage and control operations, and

3. A centralized annual budgeting system through which participants establish implicit contracts and commitments with one another to work cooperatively. 
Such a culture, in which employees and managers share expectations about future behavior (Luhmann 1979), has been effective in reducing uncertainty and promoting stability as long as market demand and competitive pressures remain relatively static. However, the traditional control culture supported by standard costing and annual budgeting is less efficient whenever changing market conditions require the firm to respond, adjust, and capitalize on new opportunities for future survival and growth. In this control culture, changes in operating capabilities are mainly managed annually as part of the capital budget. They are not anticipated during the operating cycle. In-process improvement is rare since operations are presumed to be designed in the "one best way." This creates the tendency of the MBE system to control and shape innovation, rather than sparking or inspiring learning and improvement (Ahrens and Chapman 2004, pp. 296-297) as required in a CI culture.

To counter such a tendency, this paper attempts to go one step further than merely enabling innovation. Instead, an AIS is proposed that directs productivity expansion (as in target costing) through change and innovation by systematically identifying high priority problems or events that can be improved in-process, i.e., within the operating cycle. This AIS also serves as one of the critical components of a culture-changing MCS. Modifying the traditional MCS in this way will allow accounting-based employment contracts to support $\mathrm{CI}$ and, at the same time, reduce cultural resistance to change.

\section{CONTINUOUS IMPROVEMENT ADOPTION: CULTURAL CHANGE}

When faced with new competitive pressures, firms may adopt CI practices but experience only limited success, or even failure. A key reason for these disappointing results is that employment contracts built on the existing culture provide little or no incentive for employees to actually seek improvements. However, the linear contracts introduced with CI implementation (e.g., failure rates, delivery time, customer satisfaction) are not always effective. Lambert (2001) suggests that accounting contracts should only be considered when linear contracting fails. One reason for this position is the assumption that the AIS is better aligned with company value and thus forms a more efficient basis for contractually-bounded rational decisions. Thus, realigning the AIS is a necessary component for efficient accounting-based employment contracting.

However, there are problems with contracting in practice. Participation in standard, and target-based, costing systems insures information sharing to build more accurate budgets. But this budgeting process gives employees the opportunity and incentive to build slack into their budget goals in order to reduce the risk of budget failure. Thus, in the traditional budgeting process, production standards, rather than motivating employees to utilize their knowledge and skills to improve business processes, tend to deskill, disempower, and control workers (Braverman 1974; Clawson 1980; Miller and O'Leary 1987; Hoskin and Macve 1988a, b; Ezzamel, Hoskin, and Macve 1990; Hopper and Armstrong 1991; Stewart 1992; and Walsh and Stewart 1993). Although management has adopted a new strategy of CI, the existing MCS business culture and its budget-based employment contracts may not be adequately aligned with the new strategy. Hence, the CI practices eventually prove to be disappointing, because a complementary adaptive MCS culture (Chenhall and Langfield-Smith 2003) is missing.

A solution to this problem may be to modify the current MCS to reduce shirking and resistance to a CI culture. Before discussing the design of an MCS that monitors the implementation and supports the management of the CI culture, the basic characteristics of a business culture and the particular aspects of the CI culture must first be defined.

\section{CULTURE, LEARNING, UNCERTAINTY, AND TRUST}

Culture may be defined as, "the pattern of basic assumptions that a given group has invented, discovered, or developed in learning to cope with its problems of external adaptation and internal integration, and that have worked well enough to be considered valid, and, therefore to be taught to new 
members as the correct way to perceive, think, and feel in relation to those problems" (Schein 1984). More simply, it is "the way we do things around here" (Williams et al. 1994).

Cultural norms form the bounded rationality for management decisions where "budgeting is treated as a component of the incentive-contracting system that governs the employment relation" (Covaleski et al. 2003). When profitability is an accepted norm of the business culture, accounting systems can validate new ideas and procedures. Thus, a powerful role for accounting systems is assured when new ideas can be validated by framing decisions with accounting values linked to employment contracts.

\section{ACCURATE ACCOUNTING VALUES AND BOUNDED RATIONALITY FOR IN-PROCESS CONTINUOUS IMPROVEMENT}

This research examines a CI business culture practicing continuous improvement at the operating level. Continuous Improvement and change are accepted normative values and are part of day-to-day operations. The company used to illustrate a CI-AIS already possessed a strong customer focus as part of their strategic success. Their concern was that their "customer first approach" was just getting too expensive. This concern has been echoed in other cases as well. Unfortunately, "some managers were particularly concerned about the dysfunctional effects of the heavy emphasis placed on (performance) measures" (Chenhall and Langfield-Smith 1998; Jazayeri and Hopper 1999). By contracting with the use of accounting data, decision analysis can be bounded by the accounting system. Non-monetary performance measures aligned with strategic value can provide direction, but the economic value of improvements and the trade offs between performance measures cannot be determined without financial data. Consequently, performance measures may be only indirectly associated with accounting-based employment contracts. Performance measures that are not aligned with accounting contracts increase agency risk because decisions based upon performance measure outcomes may not coincide with accounting outcomes. In fact, adopters of lean manufacturing are warned to ignore short-term accounting results since they do not reflect the economic value of lean manufacturing strategies (Kroll 2004). Since accounting measures of in-process performance may not reflect long-term advantage, the MCS must include opportunities to estimate long-term financial values of change activities with accounting data.

The CI-AIS developed in this paper is designed for a work-based, cellular production process. Statements for each production line were developed and work teams included membership for entire process from raw materials inventories to finished goods inventories. It should be noted that at the beginning of the cultural change process, the overarching normative value of accounting profitability is a crucial validating mechanism. Even if the accounting measures do not perfectly reflect long-term value, as is often the case with performance measures, they have the advantage of being associated with the preexisting cultural norms of acceptable activities.

While employment contracting is extensively modeled in agency theory, the insights from this work are limited. Only certain extreme conditions and limited sets of variables can be adequately modeled. Agency research cannot define the proportional impact (Covaleski et al. 2003) of design considerations required in application. In spite of the limitations, however, agency insights can provide direction in the sense that more or less of a characteristic will increase or decrease risk. Thus, agency theory precepts can help to define MCS characteristics influencing contracting efficiency.

Extensive insight into employment contracting is also offered by agency theory. However, one problem with using agency theory alone to design an MCS system is its underlying assumption of the instantaneous optimal realignment of employment contracts with strategic change. Agency theory generally assumes that employees have full knowledge of the new cause and effect relationships on the welfare tradeoff between agents and principals. This notion also implicitly assumes that agents understand the manner in which their actions influence productivity measures. Unfortunately, when changing to a CI culture, learning "new ways of doing things" is not instantaneous. Realignment of employment contracts cannot occur until new rules of cause and effect are generally understood. Until agents learn the new cause and effect relationships of actions with profitability norms, they must absorb the increased risk that their actions may not produce the desired results. Thus, changing operating strategies may increase 
agency risk about the uncertainty and value of these actions until new strategies are understood. Until learning occurs, changes only encourage employee resistance because trust between agents is not sufficient to compensate for the risk associated with change. Thus, one cause of inefficient contracting and consequent employee resistance is the failure of the MCS to adequately limit the agent's risk when trust alone is not sufficient.

The tolerance for risk that agents are willing to accept is related to their level of trust. When employees cannot accurately predict the implications of new decisions facing them, they need to trust that superiors will not react negatively to their risk-taking decisions that may result in failure. Over time, as uncertainty about the consequences of new activities decreases, less trust is needed in order for agents to support new activities. Consequently, trust becomes a significant design factor for an adaptive MCS. Trust, as defined by Chenhall and Langfield-Smith (2003), is the agent's ability to predict the consequences of his or her decisions and actions in a business culture. When change is introduced, uncertainty in these predictions increases the risk attached to making decisions and taking actions. In order to foster an atmosphere of trust, agents need to be informed of the outcomes resulting from their decisions as soon as possible.

Trust provides the basis for individuals to cooperate voluntarily in uncertain circumstances requiring learning, innovation, problem-solving and openness to change (Hardy et al. 1998; Dodgson 1993; Lewicki and Bunker 1996; Gambetta 1988; Ring and Van de Ven 1994; and Barney and Hansen 1994). Such conditions of uncertainty about cause and effect are common in the CI culture. Other aspects of the CI culture that require trust include employee empowerment, risk taking, information sharing, and the shifting of responsibility from executive levels to the shop floor.

\section{TYPES OF TRUST: ORGANIZATIONAL OR PERSONAL TRUST}

There are, however, different kinds of trust. Chenhall and Langfield-Smith (2003) differentiate personal trust from organizational trust. Personal trust requires the more demanding condition of common values and beliefs. Organizational trust does not. Organizational trust grows from repeated operational exchanges, as in this paper, reinforcing the legitimacy of operating procedures and cultural norms (Sako 1998). These formal structures use contracting to "guarantee trust" and establish the basis for developing shared values and understandings (Livet and Reynaud, 1998). As the formal structure of CI processes is repeated, agents develop new CI relationships with one another and develop trust in the cultural change process.

Organizational trust promotes efficiency by allowing employees to coordinate their activities. When there is strong organizational trust, MCSs (using budgets) can focus on supporting "resource planning and communication" goals (Ouchi 1977, 1979, 1980; Merchant 1985; Macintosh 1994) and do not have to consider behavioral issues.

A key mechanism in the development, fostering, and maintenance of trust in any business culture is the AIS that provides information for decision making and learning at every level of the organization. If an AIS allows employees to measure and evaluate the implications of incremental changes in their activities in a timely manner, less trust is required by agents and risk will be reduced. As a result, improvement can proceed efficiently on a continuous basis. Thus, one important contribution of a CI accounting system should be to reduce the need for trust by limiting the agency risk attached to changing cultures.

\section{CREATING CONTINUOUS IMPROVEMENT EMPLOYMENT CONTRACTS}

When transitioning to a CI culture, the quality literature clearly identifies cultural resistance as a major factor of frustration. For example, the need to change the "them and us" relationship between operations employees and management is a recurring theme (Westrup, Hopper, and Jazayeri 2001, p. 27). In order for these two parties to work cooperatively toward continuous improvement, new contractual relationships must be established. 
We contend that such an accounting-based employment contract requires a well understood and timely budgeting system aligned with new strategies to validate changes as they occur. The CI-AIS reduces uncertainty, and hence risk, by enabling employees and managers to gauge the legitimacy of their new activities against the cost-benefit metric of corporate earnings.

Thus, when transitioning to a CI culture, the norm of profitability can enhance the productivity expansion in several ways. First, it can identify inappropriate behavior. Any activity that can be accurately identified as unprofitable can be dismissed with credibility. Second, adaptive variances can uncover opportunities for a more efficient productivity expansion path (as opposed to merely justifying MBE investigations). Third, it sets boundaries for rational analysis limited to profitability. Fourth, it can aid in contracting to reduce agency risk and increasing mutual trust, cooperation, morale, and the willingness to learn and share risk with a view toward improvement. Hence, the AIS should be designed to align employment contracts with a new culture based on the norm of profitability.

\section{A CONTINUOUS IMPROVEMENT ACCOUNTING SYSTEM USING INFORMATION ECONOMICS AND AGENCY INSIGHTS}

Unfortunately, most current AISs provide only dated, highly aggregated validation (after 18-24 months) about the value of change activities. These systems lack both the timeliness and the level of detail to significantly reduce agency risk. Numerous CI-compatible features to be incorporated into the AIS have been suggested in the accounting literature (See Exhibit 2), but a completely reliable model under all conditions, either for implementation or management of a CI culture, has yet to be offered.

Dated validation of new, innovative activities only serves to obscure cause and effect relationships at the operational level and increase uncertainty about the real economic impact of these activities. This makes the development of mutual trust and adaptive employment contracts difficult. In such an environment, if employees cannot use accounting to align a new business culture with employment contracts, they are forced to trust that the new activities will prove profitable sometime in the future. In particular, salaried employees who are expected to be motivated by company profitability, rather than suboptimal incentives such as piece rates or quality levels, may be reluctant to implement innovations required for continuous improvement if timely formative assessments are not provided.

According to the information economics literature (Itami 1977), timelier feedback allows more rapid elimination of wasteful activities. However, Itami's model does not specify a process for how adaptations are made. It merely points out that more timely or adaptive variances lead to more efficient change. Itami's model assumes that changes will be made efficiently. Given the limited number of successful CI implementations, it is not clear whether efficient adaptations will always occur. Thus, the process of adaptation should be closely examined in the implementation stage to assure success in practice. Improved feedback in and of itself is not sufficient to gain economic advantage.

To better support CI implementation, the AIS should be redesigned to complement and support both the implementation and management practices of the CI (See Exhibit 3 for a list of WCM tools (Schonberger 1991)).

\section{Trust-related AIS Design Considerations}

Chenhall and Langfield Smith (2003) attribute CI implementation failure to an insufficient level of trust between agents and principals. Trust is the willingness of agents to absorb risky actions of unknown CI processes. Thus, reducing risk lowers the level of trust required for agents to support cultural change. Risk has two elements, uncertainty and economic impact. Manipulating these factors should influence agency risk. Consequently, redesigning a CI-AIS should consider reducing these factors.

\section{Managing Uncertainty: Generating Timely Adaptive Feedback}

Timely adaptive variances can decrease the uncertainty related to productivity expansion. Each accounting report either validates or invalidates the changes made in the prior period. With accurate accounting reports, the uncertainty about productivity decisions is reduced to the next accounting report. 
The more timely the accounting report, the fewer process replications between evaluations and the less uncertainty agents must tolerate about their operating decisions. For a process-based manufacturing system, the most timely complete process cycle is determined by the individual job. If each accounting report measures a complete economic activity, then each report provides boundaries for management decisions. To the extent that the accounting report is aligned with employment contracts, the short-term risk and uncertainty about the outcome is potentially eliminated with each accounting report. Thus, decision risk can be reduced by design strategies that provide more timely feedback or adaptive variances (Itami 1977 Ijiri and Itami 1973). A system reporting new actions in a more timely fashion will reduce the cost of errors when adopting new strategies by limiting the time until adaptations or corrections can be made.

\section{Managing Economic Impact: Limiting Loss Through Incremental Reporting}

In addition to uncertainty, the potential loss function also influences the level of agency risk. Smaller economic loss means less risk for decisions about uncertain outcomes. Thus, in addition to timeliness, feedback on more incremental decisions also reduces risk by limiting the loss function to these incremental decisions. A minimal complete measure is the measurement of one complete production cycle. Each job is a unique production cycle defined by product type and volume. Reporting by individual completed job rather than a fixed temporal reporting period provides the most timely and incremental feedback on complete economic activities to reduce both uncertainty and economic loss.

\section{Managing Participation Costs: Prioritizing Decisions to Limit Shirking}

New business cultures that emphasize learning present management and employees an "incomplete market" that is ideal for budget-based employment contracting in which employees' knowledge and effort are not observable by management. "In complete markets, all information is public, enabling owners to construct contracts with employees based on the level of effort that the employees would supply as well as on the employee's skill" (Covaleski et al. 2003). Agency theory (Baiman and Evans 1983; Penno 1984) suggests that, under these conditions, participative budgeting, in which agents share private information with owners, is superior.

Learning, however, is a private matter in which effort and private information are not clearly visible. Participation, as defined in agency models, would appear to at least partially apply to CI strategies but not completely, since agents may not have complete information about cause and effect. Unfortunately, private information and unobservable effort still create the opportunity, and budget-based contracts provide the incentive, for shirking and building slack into budget estimates because the optimal solutions are unknown among agents and principals.

When optimal solutions are unknown, the MCS can only direct and manage the process of discovery, presenting some challenging agency problems. First, there is the problem of self-selection bias. As incremental CI continues, agents can shirk by astutely selecting projects that minimize personal risk instead of choosing more optimal organizational solutions. Overcoming this problem with increased compensation may be a costly solution. A more efficient solution, offered in this paper, may be to create an AIS that reduces self-selection bias by identifying the CI expansion path. This allows MCSs to be designed to mitigate contracting failure by reducing the opportunities for shirking and building in slack.

In-process CI leading to lean manufacturing requires a process focus. The costing objective for each cycle is the individual batch or job which demonstrates a completed activity. Thus, each job offers the opportunity for a process system evaluation and, consequently, incremental "process" improvement. Incremental prioritization means reporting on each specific in-process job. By ranking completed jobs based on levels of waste, CI opportunities are highlighted by the AIS. The entire universe of jobs is not selected but rather just a few opportune outliers identified by accounting reports. There is little opportunity for self-selection bias and shirking. The risk of economic loss is limited to the particular job selected rather than the entire process. This incremental approach further reduces agency risk caused by the uncertainty surrounding CI approaches. 
For in-process improvement, the use of perfect standards, rather than practical or engineered standards, allows the variances to capture more opportunities for improvement and limits opportunities to build in slack. Any variance from perfection is considered waste. The larger the waste variance the greater is the potential for identifying an inefficient practice caused by current process activities. Unlike negotiated variances, AIS measures, based on perfect job standards, will provide waste variances that reflect the greatest potential for process improvements while limiting opportunities to create negotiated or hidden slack. Simply, the perfect rated engineering standards, the vendor formulas, and perfect material inputs are used as standards. On average, the largest waste variances should provide the greatest opportunities for improvement over existing practice. Even when better opportunities exist, waste variances are superior for cultural change since they are unambiguously related to budgets used for employment contracting. Such performance measures are culturally acceptable in both pre-existing and current cultures, providing validation for analysis and change.

To summarize, design characteristics of an adaptive AIS should consider contracting efficiency with incremental, timely reporting that directs CI, identifying the successes and failures of incremental innovations. Information of this type, as part of an MCS, can improve productivity while supporting cultural change.

The CI-AIS needs to complement an MCS that 1) promotes learning new norms of behavior and culture, and 2) fosters alignment of employment contracts with CI business strategies. Typically, agency models assume instantaneous realignment and full knowledge of the cause and effect relationships for contracting. However, this is not the case when cultural change occurs. Agents in a CI culture, by definition, must learn "new ways of doing things." However, agency theory and information economics models add little insight to efficient learning strategies. A more efficient alternative theoretical model is required for this purpose.

\section{USING CONSTRUCTIVIST LEARNING THEORY}

An efficient CI-MCS must facilitate learning. To improve contracting efficiency, agents need to understand the relationship between their actions and accounting outcomes. These relationships form a significant part of the business culture. Since instantaneous learning is assumed in agency models, little insight into designing learning systems can be offered from agency theory. However, an alternative theoretical perspective, as suggested by Covaleski et al. (2003), using constructivist learning models from the educational literature, provides implementation insight. In constructivist learning, people build new knowledge from "what they already know and believe" (Bransford et al. 1999). The constructivist approach to learning relates new ideas to preexisting, familiar ideas that have already been validated to be effective and profitable. This is a very efficient way to learn (Baron et al. 1998; Black and William 1998).

Constructivist learning uses pre-existing knowledge to build new knowledge. In our model, this preexisting knowledge is the prior business culture. Constructivist learning does not eliminate the introduction of new learning entirely but rather parsimoniously merges new ideas with pre-existing knowledge. The efficiency of this approach is linked to the way the brain processes new knowledge. Juxtaposition is a powerful and basic form of learning ${ }^{1}$. It is the relevant differences between the new and the old that make the new idea unique. In this sense, new knowledge is additive (or constructive). A new idea is "all the things the brain has in common already" plus these "relevant differences." For example, to understand the new idea of blue fire hydrants, the brain takes the pre-existing knowledge of a red fire hydrant and only adds one piece of information - the new color. The closer the fit between the new and pre-existing concepts, the less there is to learn and the more brain-friendly is the new idea (Mackey 2004). The less innovative the new ideas, the easier they are to learn and embed into current understanding. New ideas are context-related (Schank 1990). Limiting the variations in context will make learning easier. In fact, the more incremental the new knowledge is from the old, the easier the new concepts are to learn. 
Consequently, utilizing existing contracts with a similar AIS validation may be more efficient than introducing new, unfamiliar contracts that ignore costs and are based solely on customer satisfaction, error rates, or delivery times.

\section{Formative Assessments}

Finally, formative assessment (determining the correctness of ideas as the new culture is forming), rather than merely summative assessment (determining the correctness of new ideas after the culture is in place), is a key component of constructivist learning. An apt analogy is learning how to swing a golf club. Learning requires mastering a set of sequential activities. Formative evaluation breaks the swing into its incremental "formative" components - i.e., the stance, the positioning of the ball, the hands, etc. Using the formative assessment approach, each component is evaluated separately as it is formed or put into action. Thus, each step logically follows the learning-assessment-learning sequence until the entire golf swing is mastered. Summative assessment, on the other hand, would only use a final assessment of the flight of the ball to determine appropriate understanding and acquisition of the golf swing. The results of such an approach are obvious when the learner takes his first golf lesson. If his stance is incorrect, then all the other following activities he learned are likely flawed as well, since they all have been constructed on a flawed premise. With a summative assessment, the correction of the stance requires every step that follows his initial incorrect stance to be rebuilt. This process can be very difficult since the body is erroneously convinced that the flawed constructs are correct. Formative assessments allow corrections early in the process so that only the golfer's stance, and not the entire process, needs to be corrected.

Unfortunately, as any golfer will attest, when misconceptions occur, they may be nearly impossible to reverse. To avoid this problem, efficiencies in learning are gained by evaluating new ideas in a timely manner through formative incremental assessment and facilitating collaborative consensus among learners. Without formative assessments ${ }^{4}$, dangerous and inefficient misconceptions can occur and lead to an accumulation of knowledge that is based upon false assumptions. The problem is that ideas built on a foundation of pre-existing knowledge take on the strength of the original familiar ideas. Should the new learning be incorrect, these errors will be confounded by distorting subsequent conclusions. To avoid this problem and to minimize errors, timely formative assessments are necessary.

\section{Collaboration}

A second design feature suggested by constructivism is collaboration for active learning. Schank (1990) identifies specific steps the brain uses to store memories ${ }^{2}$. The final step is discussion. Collaboration allows individuals to discuss their new insights to better formulate their understanding of the new ideas. Collaboration is also important since this utilizes active learning (i.e., learning by doing). Working collaboratively also "increases the quality of feedback" for learners (Bereiter and Scardamalia 1989; Fuchs et al. 1992; Johnson and Johnson 1975; Slavin 1987). Collaboration is more than simply sharing private information. When learning new cultures, the private information may be incomplete and incorrect. Thus, collaboration is not the same as participation, which assumes full knowledge of cause and effect. Rather, collaboration includes the actual learning of cause and effect by demonstrating and modifying one's understanding through discourse and actions. In a learning model, participants share private information to modify and validate their understanding of new actions and applications of processes.

Thus, when designing a MCS that promotes instruction and change, the incremental assessment of changes in a timely manner provides for more efficient learning. Further, constructivist learning theory suggests that after the AIS identifies specific incremental problems, workers (i.e., managers and employees) should collaborate in a drill-down analysis to find a correctable root cause for the problem. Collaboration enhances learning (and spreads the risk of failure among participants) while developing a consensus on the best solution. With the view that cultural change involves learning a new set of acceptable norms of conduct, applying the principles of constructivist learning to CI builds on preexisting knowledge and uses accounting data as an assessment base to prove to the learner that the new way is better. 
To summarize, constructivist learning theory is improved by adaptive variances since incremental economic reports provide a formative assessment of CI changes. In order to change the business culture, evidence must be presented to verify that changing the way things are done will increase company value. A CI culture includes a belief that there is always a way to improve. Selecting and evaluating a series of changes that are validated with the CI-AIS allows employees to learn using contracting data. This is unlike current MCSs where nonfinancial measures of assessment dominate and are not validated by timely accounting measures of value. Existing implementation processes lack formative economic assessment and thus, require much higher levels of trust to succeed, making them prone to failure.

\section{THE IN-PROCESS BUDGETING SYSTEM: MAKING EFFORT AND ADAPTATION VISIBLE}

Adapting to a new culture is a learning process. Feedback from adaptive variances complements constructive learning by providing both an observable productivity expansion path and a timely assessment to validate the change process. An observable productivity expansion path is important for cultural change to assure that change activities support CI activities. From a learning theory perspective, prioritizing waste activities directs the learning of both the new CI culture and subsequent CI management. From a constructivist learning perspective, each investigation offers an opportunity to introduce cultural change into "the way things are done." Consequently, once validated by the accounting system, each new change then reinforces the validity of previous changes and adds support for a new culture of CI (Sako 1998).

Installing a visible budgeting process will reduce the problem of unobservable actions. Visible CI processes have been successful but the role of accounting contracts in these situations was typically not disclosed. This insight leads to a conclusion that increasing the visibility of agency activities will reduce the need for accounting contracts and lessen agency risk from unobservable actions. Group participation and collaboration makes problem-solving and learning efforts more visible to management. With visible processes in place, agents' learning activities are accounting-directed and are not self-selected. Thus, effort levels are more observable, removing many of the traditional agency problems concerning effort and knowledge asymmetries. Making the learning activities more visible will further reduce contracting inefficiencies. The design of the AIS must complement the MCS. Specifically, the MCS designed on these theoretical insights uses an in-process budgeting system to improve productivity through CI and introduce a CI business culture.

The in-process budgeting cycle is recursive and involves four steps:

- Prioritizing problems using perfect standards,

- Analyzing the root cause of problems using CI tools,

- Collaborating to design changes using current and projected cash flows, and

- Validating changes using CI accounting systems.

\section{First: Prioritizing Problems Using Perfect Standards}

For in-process CI, ranking jobs by waste variances allows the AIS, and not management, to select activities for improvement. By selecting the activities with the greatest accounting-specified waste, the probability that improvements will be aligned with employment contracts is enhanced. From a cultural change perspective, it is important that changes to "the way we do things" be validated using current employment contracts. Accounting-based employment contracts allow individuals to make decisions within the bounded rationality of existing budget data. As changes are made, agents learn the relationship between the new CI culture and accounting contracts. If the activity selected is already optimal, no change and no learning will be validated. The new ways of conducting business will not be proven superior to the old culture. 


\section{Second: Analyzing the Root Cause of Problems Using Continuous Improvement Tools}

The second step in the in-process budgeting cycle is to analyze the root cause of the waste variance using CI tools. The strategy for this step is to drill down to discover root causes that will lead to improvement. This requires group participation and collaboration to further reduce agency risk and improve decision making.

\section{Third: Collaborating to Design Changes Using Current and Projected Cash Flows}

Third, agents should collaborate to design changes using current and projected cash flows. Once a root cause is identified, employees with various perspectives will collaborate to find and take responsibility for solutions. As with the prior step, collaboration within existing accounting-based employment contracts reduces agency risk and limits shirking opportunities since deliberations are visible. This process of collaboration pools pre-existing asymmetric group knowledge to provide the most informed strategy for improvement. The CI-AIS should provide information that will facilitate strategic analysis of current cash flows and projected future cash flows. Determining appropriate change activities should include the strategic goal of greater cash flows over numerous periods.

Achieving greater cash flows over numerous periods could be a problem if immediate process improvements require investments that are only justified over many operating periods. The accountingbased employment contracts need to be consistent with this economic analysis. Our application in the manufacturing setting decoupled the investment decision from the subsequent process validation. In the lift truck example, the monies for the additional truck were justified over projected future cash flows but the validation of the improvement was demonstrated by subsequent production runs. Nonetheless, using accounting-related cash flows for the change decision was still consistent with the profitability norms of pre-existing and CI cultures.

\section{Fourth: Validating Changes Using Continuous Improvement Accounting Systems}

Learning within the bounded rationality of incremental waste opportunities, the new CI culture evolves. As decision makers receive validation of their decisions, they learn the CI process and affirm the CI culture. As this process is repeated, validating each change with AIS reports, employees learn new cause and effect relationships about CI cultures. This knowledge reduces their uncertainty about the outcomes of CI efforts. Thus, the risk of and reasons for resisting CI are reduced. Because improvement is evident and the level of individual uncertainty is reduced, employees require lower levels of trust to cooperate with the new culture.

This constructivist learning cycle, using adaptive variances, is repeated and embedded in a CI-MCS culture. The CI-MCS encourages acceptance of a new culture by offering incremental changes to preexisting cultural norms and is designed to minimize agency risk associated with changing to a new culture.

\section{THE APPLICATION}

Using an innovation action research ${ }^{5}$ approach, the abovementioned points provided guidance for a new implementation process applied in the manufacturing setting (see Exhibit 4) of the American Canning Factory (ACF). ACF is a family-owned canning plant with four different production lines, two of which (the canning lines) were the focus in this research. The company makes almost 300 different products. Each line has a tightly integrated system of machines sequentially linked by conveyor belts. For each line, the filler machine is where the product is mixed and packed and is designed to be the constraint that paces the canning line.

Consistent with other CI approaches the focus of the cost report is on the management of the process. The smallest measure is a job which includes all the activities in a complete work cycle. The job unit of measurement is considered relevant because it coincides with product line information needed for strategic decisions. Consistent with the application of action research, the information reported on the job cost card was developed collaboratively with the CI team. This collaboration resulted in the inclusion of 
the filler efficiency ratio, fixed and variable costs, and packing costs. The data has been modified but the report is identical to that used in the company. An actual report in Exhibit 5 illustrates these points. The filler efficiency is the actual production rate divided by the expected rate expressed as a percentage. The rest of the report data include fixed and variable costs for both run and setup time as well as waste. Waste was broken out as nonvalue adding costs. Packing costs are culturally relevant since these are controllable by the cell and are critical to the bidding of custom jobs.

The support costs for each production line are grouped into separate cost pools and reassigned as capacity costs using the scheduled capacity on the filler machine. Cost pools, and cause and effect relationships were determined through staff interviews. To improve accuracy, five cost pools were selected - general overhead, materials, hourly labor, supplies, and power. The costing object is each production run of a particular product.

Since the filler paces the line, this creates a theory of constraints application. The capacity of the constraint sets the capacity for the entire production system, so improvements at the constraint have an immediate and measurable impact on productivity. Overhead costs are assigned based upon the time in the cell using scheduled/capacity available for production (Mackey and Hughes, 1993).

Each job run was assigned ingredients costs, variable manufacturing costs, variable setup costs, fixed setup overhead costs, fixed value-adding overhead costs, and non-value adding waste. For each category, total standard costs and actual costs, as well as unit costs with variances, are calculated. Variable manufacturing costs are calculated using perfect standards which include hourly labor costs, power, supplies, and repairs. Variable setup costs only include hourly labor, supplies, and repairs. Power is not used when the machines are stopped for setup. Fixed costs are assigned based upon the scheduled capacity in minutes of filler runtime. Nonvalue adding waste is assigned both a variable and a fixed capacity charge for the cost of the production capacity provided. This includes short-term and long-term savings associated with the elimination of waste. Adding capacity through reduced waste is the long-term saving. Shift and runtime costs are related to the variable costs. The fixed capacity costs should also result in long-term savings. They are included because management uses full costing to articulate with the financial statements.

Because of the perfect standards, very few jobs have a positive (or favorable) variance (see Exhibit 6). Most jobs have negative (or unfavorable) variances. This is a critical philosophical difference between this costing system focused on continuous improvement and the traditional system. In the CI system, unfavorable variances do not indicate work is inefficient. The importance of the nonvalue-adding variances is that they highlight a particular opportunity for improvement. The job with the greatest variance is the largest outlier and should represent the most significant opportunity for improvement.

The jobs for the month are ranked from the largest to the least waste variance per case ${ }^{6}$. A root cause analysis is then performed on the worst three jobs and the best three jobs. The reasons for the waste are classified as either systems-related or product-related failures. Systems-related failures are activities that, if corrected, will improve production for all products and generate savings across all product lines. Product-related failures are activities that are due to the particular jobs, or products, themselves. The difference in these two classifications is important for subsequent strategic analysis.

\section{A Full Costing Paradox}

At the canning company, product and waste costs are assigned using full costing. This is preferred for CI strategic costing for several reasons. First, fully allocated costs that are articulated with the financial statements are consistent with the existing business culture's interpretation of cost. This allows the unit costs to be consistent across the organization. Second, assigning fixed costs based upon available capacity provides a better measure of the costs of providing capacity. Using a full capacity denominator produces an idle capacity variance that can be used to signal the reduction of waste and the need to revise cost driver rates.

However, improved productivity results in fewer shifts required for the same production volume making it difficult to appropriately assign fixed costs to products. In the short-term for CI management, the impact is minimal, but over the long term these rates will be revised periodically. As a practical 
matter, the projects chosen for improvement depend on their relative ranking. Marginal differences have little impact. All of the initial projects suggested required very little investment. The savings from waste reduction far out-weight the cost.

The real importance of assigning fixed costs is the influence the costs have on justifying a continuous improvement culture because more value is placed on eliminating waste.

Each of ACF's products has a unique formula using proprietary syrup and other ingredients like sugar and foaming agents. The company's vendors provide the yield specifications for each product. For example, one product may produce 200 cases while another product (of equal volume) produces 300 cases. Each has their bill of materials specifying the mix of proprietary syrup, sugar, foaming agents and other inputs. Specifications like these are used to set standards at ACF based on perfect production. This total quality approach makes no allowance for waste, even though it might reasonably be expected. If the production activity is perfect, then the machine and ingredients specifications will be met exactly. The objective of the reporting system is to identify the cost of total waste, not just the unexpected or unnegotiated waste. Agency negotiations are eliminated and the control contracts are modified appropriately. In so doing, the problem with the greatest opportunity for profitable improvement is prioritized and highlighted.

CI begins by analyzing nonvalue cost, or waste, which is simply the additional consumption over these perfect standards. All jobs (processes) are then ranked by level of waste and analyzed. The largest negative variances from the perfect standards highlight the greatest opportunities for improvement. A root-cause analysis then reveals the suspected cause or causes of this waste. Based on this analysis, action plans to reduce the waste are then devised and implemented.

\section{OPPORTUNITY \#1: SUGAR-FREE FLAVORS}

\section{Systemic Improvement}

One instance of a CI decision at ACF involved sugar-free flavors. According to the variance reports, a sugar-free product had one of the largest waste variances for the month (see Exhibit 6).

It should be stressed that waste must be reported in terms of monetary cost in order to tie variances to the overarching cultural norm of profitability. When productivity yield measures alone were used at ACF, important problems were ignored and opportunities for improvement were neglected. By themselves, productivity measures prompted no action because they were detached from and unrelated to the shared value of profitability held by all employees at ACF.

To illustrate, run inefficiency/waste of Papa's Soda is translated in terms of profitability, indicating a $\$ 1.73$ negative variance from the perfect standard per case (Exhibit 6). No other product had a negative variance this high. Focusing on Papa's Soda, drill-down analysis for the process by the work team indicated that the equipment used to produce this product was adding syrup at levels higher than the vendor specifications. It was agreed that new equipment needed to be purchased in order to correct the problem, reduce the waste, and increase the profitability of Papa's Soda and other lines using the same equipment.

Interestingly, this problem was systemic and common to many more products. In this instance, the analysis of the greatest outlier job offered opportunities to improve all the processes, not just a single product line.

\section{OPPORTUNITY \#2: THE LIFT TRUCK}

\section{Superficial or Immediate Solution}

A second example at ACF involved a lift truck on a product line. According to the perfect standards, this job was excessively expensive because of downtime. The drill-down investigation indicated that the product for this job required a longer drive to the storage area than other products. At the time, only one lift truck was available and periodically the production line had to be stopped to allow the lift truck to catch up. Consequently, excessive inventory piled up at the packer. Eventually, the entire production line 
with the new CI-AIS had to be closed down and the downtime was charged to the cost of the product. Based on perfect standards, the variance report clearly revealed that the time wasted in moving inventory with only one lift truck was making the product too expensive. The decision was then made to purchase an additional lift truck to reduce downtime and improve this particular product's profitability. Because the AIS highlighted the problem as a top priority in terms of profitability, the necessary remedy was obvious and straightforward to everyone who participated in the collaborative decision process. Hence, the beginning of a CI culture with a CI-AIS was launched.

\section{SUMMARY}

MCSs use an array of tools to support the achievement of strategic and operational goals. This paper describes an innovative action research approach to improving the implementation of a CI culture. In short, developing an AIS to support the adoption of the CI culture involves the understanding and implementation of the following points:

- The most significant reason for failure in becoming a CI organization is cultural resistance.

- Cultural resistance to value-adding strategies is caused by contracting failures.

- Design features of the MCS influence the efficiency of employment contracts.

- Culture change is the result of learning new ways to do things.

- Constructivism is the most efficient way to learn (Bransford et al. 1999) because pre-existing knowledge from the current culture is used to incrementally create new knowledge with formative assessments (Baron et al. 1998; Black and William 1998) that limit uncertainty.

- A CI-AIS that provides timely, accurate, in-process, incremental performance measures for formative assessments based on the pre-existing cultural norm of profitability will foster the successful change from a control culture to a CI culture.

- Such a CI-AIS must be embedded in an appropriately-designed MCS that builds a recursive management process, allows the merging of strategic and operational values, and supports work team collaboration, allowing for more efficient implementation and management of CI strategies.

In general, when accounting-based employment contracts exist, agents make decisions within the bounded rationality provided by the accounting system. To motivate a change in culture using accounting-bounded information, a MCS must be capable of repetitively: 1) identifying high priority waste variances for evaluation, 2) facilitating the collaborative process of root-cause analysis and strategic cost/benefit analysis, 3) supporting the process of proposing change activities, and 4) validating changes that lead to learning and adopting a new culture.

As predicted by Covaleski et al. (2003) the theory did not adequately inform its application. Therefore, multiple theories in combination were applied to provide a workable solution.

\section{Informing Information Economics}

Itami (1977) suggested that more frequent variance reporting reduces the cost of out-of-control conditions. However, because of the standard-setting problem of shirking, the timeliest measure of one complete job was used.

Impounding value into accounting numbers has always been a problem in practice. To make optimal valuation decisions, activity choices must include both current and future cash flows. The necessity of using hard data for accounting systems creates a suboptimality condition when relevant future cash flows are not part of the data set. The pragmatic solution to this problem was to create a MCS establishing strategic boundaries on operational decisions. For optimal decisions, both strategic and operational considerations must be included. Thus, all change decisions were made within the bounded rationality provided by strategic considerations. This approach explicitly includes strategic issues in the offered solutions for CI. 


\section{Informing Agency Theory}

Our application relies on the agency concepts of accounting contracts, organizational risk, trust, and shirking behavior leading to employee resistance to change. In this social context, the importance of accounting outcomes was well established as a justification for change within a bounded strategic context.

The agency theory insights into risk and moral hazard issues were central to the design of the CI MCS. These insights led directly to the design criteria to minimize uncertainty and potential economic loss as changes and 'new ways to do things' are impounded into the business culture. While the specific design features that reduced risk where not directly suggested by agency theory, it did provide direction in seeking mechanisms that limit risk while using accounting contracting to validate CI. Ultimately, the performance of the CI-MCS seemed to validate the theory.

\section{Informing Constructivist Learning Theory}

When economic and agency theories assume instantaneous adaptation, they provide little insight into implementing change even though organizational change is rarely frictionless and often extremely difficult due to vested social interests. Alternative constructivist learning theories provided more pragmatic guidance for field implementation. By treating normative values as learned behavior, the application of learning theory to the problem of cultural change is informative. As agents learn the cause and effect relationship of their actions, they can better predict the results of their actions and reduce the risk of failure. Their ability to predict the results of CI decisions reduces the risk and the level of trust agents need in order to avoid shirking behaviors. From our application in this social context, the theories that explain mathematics, sciences, or languages seem to apply to social settings where agents learn a new culture. Formative learning techniques are not merely superior for learning but also coincide with the reduction and limitation of risk from an agency perspective. The shared collaboration that supports active learning also reflects the idea of participation and reduced individual risk by shared decision making in teams. The participative learning and formative validation techniques used in the CI-MCS seem to have effectively reduced the perceived risk from making CI decisions and hence, reduced the resistance to change. Whether this will be sufficient in all circumstances is an open research issue, but the results of this application seem promising.

\section{CONCLUSION AND FUTURE RESEARCH}

The first three steps of an innovative action research approach are to identify the problem, use existing research to offer a new solution, and apply the solution. After identifying the problem of resistance to cultural change, this paper offers a solution for implementing and managing CI using existing research and then applies it in practice. As offered by Kaplan (1998), the elements of the application that have merit will be amplified and developed in future improvements in the fourth innovative action research stage - improvement. Over the six months of development and implementation, throughput for the work center in our research case improved 35 percent, and after a period of two years the company is still using the AIS system for process management.

While successful CI companies have clearly demonstrated performance advantages, the process of conversion to a CI culture has proved to be difficult in practice. Despite a long history of using accounting information to justify operating decisions, accounting validation for CI implementation and management is deferred to extended reporting periods. WCM implementation assessment, for example, may take 18 to 24 months.

Introducing a new business culture requires employees to learn a new "way to do things." Oftentimes, the prospect of learning and changing is met with resistance. Agents resist change activities when their tolerance for risk is exceeded. This paper demonstrates a MCS designed to limit agency risk. The MCS incorporates aspects of several theories, including information economics, agency theory, and constructivist learning theory in order to achieve efficient productivity expansion and increased profitability. An innovative action research approach is employed to implement the combination of these theoretical solutions in a manufacturing environment. 
Finally, a caveat needs to be offered. CI introduces a dramatic change in the day-to-day operating culture of a business. Contingency theory suggests that there is no generalizable superior design solution for all management accounting and control situations. However, techniques such as WCM tend to introduce a universal approach where the opportunities for strategic adaptation are bounded by the length of the accounting assessments. Ijiri and Itami argue that longer adaptation reporting periods lead to less efficient productivity expansion. Operationalization of this theoretical insight to the implementation of CI offers potential evidence of this inefficiency in the resistance to CI implementation and the incremental approach to change adopted by some organizations.

Quattrone and Hopper (2001), however, also noted the results of different implementation approaches in practice. Contrasting the implementation of SAP in two multinational organizations, a prescriptive approach involving a redesign of processes to coincide with "world class" practices, was contrasted with an incremental approach, installing SAP to fit existing practices and to continue incrementally. They concluded that "control is then no longer about prescribing 'right' courses of action but describing 'possible' courses of action." Following on Munro's "centers of discretion," they argue that research is needed to study "how accounting destabilizes organizations" within the context of creating knowledge. To complement and extend Quattrone and Hopper, we conclude that when complete knowledge of cause and effect is available, proscriptive solutions may be suitable. However, when uncertainty exists, room for creative, adaptive accounting solutions must be provided.

This conclusion leads to additional insight. Might, in fact, some of the cultural resistance to the implementation of CI cultures be optimal? Might, in fact, the global implementation of CI tools create inefficiencies that would not occur with an incremental solution? Unfortunately, the converse could be argued as well. Upton and Kim (1998) found a propensity for successful improvement strategies to continue even when providing declining returns. Thus, an inefficient productivity expansion path may evolve when the in-process reports alone are used to provide CI guidance.

The approach advocated in this paper has thus far proved to be promising in just one situation. Further analysis and research is both justified and necessary to examine the generalizability of this CIMCS. However, success from a single application need not be completely generalizable to advance knowledge or benefit from such research (Kaplan 1998) because solutions evolve with practice. The acceptance and value of such research will be demonstrated in its continued use.

\section{ENDNOTES}

1. In perceptual learning "contrasting cases" allows students to notice features more efficiently (Gagne and Gibson 1947; Garner 1974; Gibson and Gibson 1955). The power of contrasts also works for conceptual learning (Bransford et al. 1989).

2. First, the story is summarized into the key elements of the experience. Then, activities are sequenced into a story. Each event triggers the next. By stringing events or thoughts together in a related story, each subsequent thought is placed into the context of the previous event. Since memories are context-embedded, the context enhances recall. Contexts with characteristics similar to new ideas provide additional learning anchors to enhance recall. Third, the brain uses "learning anchors" to index key concepts allowing events to be easily recalled. Fourth, we tell the story using conversational language. Not only does discussion build and strengthen synaptic connections, but also conversational language is generally more powerful because it is used more often. The strength of a synaptic connection increases with use. Thus, conversational language is more brain-friendly than technical language.

3. 'In Fortune's all star ranking, General Electric earned the highest honor in 1998 since it has spent years developing a corporate culture in which executives have the autonomy to swoop in and take advantage of sudden shifts in markets." - (Kahn 1998)

4. Formative assessments refer to corrective feedback that takes place during the learning process. This is contrasted with summative assessments which are the evaluative and corrective testing of new ideas after the learning process is complete.

5. Innovation action research engages the researcher in an explicit program to develop and implement entirely new approaches. It involves 1) identifying the problem in practice, 2) explaining a new solution to the problem justified with existing research or theory, 3) applying it, and 4) improving it (Kaplan 1998). 
6. This ranking allows another opportunity for design contingencies. Management is particularly interested in making product line and strategic decisions. Thus factors influencing case costs per unit were identified to be of the most interest. Using the total waste cost would allow large product runs to dominate over small product lines. The rule could be changed as the system evolves.

\section{REFERENCES}

Adler, P.S., \& Borys, B. (1996, March). Two types of bureaucracy: Enabling and coercive. Administrative Science Quarterly, 41(1), 61.

Ahrens, T., \& Chapman, C.S. (2004). Accounting for Flexibility and Efficiency: A Field Study of Management Control Systems in a Restaurant Chain, Contemporary Accounting Research, Toronto: Summer, 21(2), 271.

Baskerville, R., \& Myers, M. (2004). Special Issue on Action Research in Information Systems: Making IS Research Relevant to Practice - Foreward. MIS Quarterly, 28(3), 329-335.

Barney, J. B., \& Hansen, M. H. (1994). Trustworthiness as a source of competitive advantage. Strategic Management Journal, 15, 175-190.

Barron, B.J., Swartz, D.J., Vye, N.J., Moore, A., Petrosino, A., Zech, L., Bransford, J.D., \& the Cognition and Technology Group at Vanderbilt. (1998). Doing with understanding: Lessons from research on problem and project-based learning. Journal of Learning Sciences, 7(3 and 4), 271-312.

Black, P., \& William, D. (1998). Assessment and classroom learning, In Assessment and Education. Special edition of Assessment and Education. Principles, Policy, and Practice, 5(1), 7-75. Carfax Pub. Co.

Bohoris, G.A. (1995). A comparative assessment of some major quality awards. International Journal of Quality and Reliability Management, 12(7), 30-43.

Bransford, J. D., Brown, A. L., \& Cocking, R. R. (1999). How People Learn: Brain, Mind, Experience, and School. Washington, D.C., National Academy Press.

Braverman, H. (1974). Labor and monopoly capital. Monthly Review Press, New York.

Calori, R., \& Sarnin, P., 1991. Corporate culture and economic performance: A French study. Organisation Studies, 12(1), 49-74.

Chenhall, R., \& Langfield-Smith, K. (1998). Factors influencing the role of management accounting in the development of performance measures within organizational change programs. Management Accounting Research, 9, 361-386.

Chenhall, R., \& Langfield-Smith, K. (2003). Performance measurement and reward systems, trust, and strategic change. Journal of Management Accounting Research, Annual 15, p117(27)

Clawson, D. (1980). Bureaucracy and the labor process: The transformation of U.S. industry, 1860 1920. Monthly Review Press, New York.

Corbett, L.M., \& Rastrick, K.N. (2000). Quality performance and organizational culture: A New Zealand study. International Journal of Quality \& Reliability Management, 17(1), 14-26.

Covaleski, M.A., Evans, J.H., Luft, J.L., \& Shields, M.D., (2003). Budgeting Research: Three Theoretical Perspectives and Criteria for Selective Integration. Journal of Management Accounting Research, 15, 3-49.

Dodgson, M. (1993). Learning, trust, and technological collaboration. Human Relations, New York, $46(1), 77$.

Ezzamel, M., Hoskin, K., \& Macve, R. (1990). Managing it all by numbers: A review of Johnson \& Kaplan's Relevance Lost. Accounting and Business Research, 20(79), 153-166.

Fleischman, R. K., \& Tyson, T. (1996). A guide to the historical controversies and organizational contexts of standard costs. Journal of Accounting Education, 14(1), Spring, 37-56.

Gambetta, D. (1988). Trust: Making and Breaking Cooperative Relations. New York, NY: Basil Blackwell. 
Hardy, C., Phillips, N., \& Lawrence, T. (1998). Distinguishing trust and power in interorganizational relations: Forms and facades of trust. In Trust Within and Between Organizations, edited by C. Lane and R. Bachmann, 64-87. Oxford, U.K.: Oxford University Press.

Hope, J., \& Fraser, R., (2003) Beyond Budgeting. Harvard Business School, Boston.

Hopper, T.M., \& Armstrong, P. (1991). Cost accounting, controlling labour and the rise of conglomerates. Accounting, Organizations and Society, 16(5/6), 405-438.

Hoskin, K.W., \& Macve, R.H. (1988a). The genesis of accountability: The West Point connections. Accounting, Organizations and Society, 13(1), 37-73.

Hoskin, K.W., \& Macve, R.H. (1988b). Cost accounting and the genesis of managerialism: The Springfield armory episode. In: Second Interdisciplinary Perspectives on Accounting Conference, University of Manchester.

Ijiri, Y., \& Itami, H. (1973). Quadratic Cost-Volume Relationships and Timing of Demand Information, The Accounting Review, XLVIII, October, 724-737.

Irani, Z., Beskese, A., \& Love, P.E.D. (2003). Total Quality Management and Corporate Culture: Constructs of Organisational Excellence. Technovation, 23

Itami H., (1977). Adaptive Behavior: Management Control and Information Analysis, Volume No. 15. Studies in Accounting Research, American Accounting Association, Sarasota, Fl.

Jaikumar, R., \& Bohn, R.E. (1992). A Dynamic Approach to Operations Management: An Alternative to Static Optimization Jaikumar, International Journal of Production Economics, Amsterdam, 27(3), 265.

Jazayeri, M., \& Hopper T. (1999). Management Accounting Within World Class Manufacturing: A Case Study, Management Accounting Research, 10, 263-301.

Kahn, J. (1998). The World's Most Admired Companies. Fortune, 138(8), 206-216.

Kaplan, R. (1992, November). In Defense of Activity-Based Cost Management. Management Accounting, 58-63.

Klein, R.G.L., Bigley, G.A., \& Roberts, K.H. (1995). Organisational culture in high reliability organisations. Human Relations, 48(7), 771-793.

Kotter, J. P., \& Heskett, J. L., (1992). Corporate Culture and Performance. New York: The Free Press.

Lakhe, R.R., Mohanty, R.P. (1994). Total quality Management: Concepts, Evolution and Acceptability in Developing Economies. International Journal of Quality \& Reliability Management, 11(9), 9-33.

Lambert, R.A. (2001). Contracting Theory and Accounting. Journal of Accounting and Economics, 32(13), 3-87.

Leonard-Barton, D. (1992). The Factory as a Learning Laboratory. Sloan Management Review, 34 (1)

Lewicki, R. J., \& Bunker, B. B. (1996). Developing and maintaining trust in work relationships. In Trust in Organizations, edited by R. M. Kramer, and T. Tyler, 114-139. Thousand Oaks, CA: Sage Publications.

Lewis, D. (1996). The organizational culture saga - from OD to TQM: A critical review of the literature. Part 2-applications. Leadership \& Organization Development Journal, 17(2), 9-16.

Luhmann, N. (1979). Trust and Power. Chichester, U.K.: John Wiley \& Sons.

Mackey, J. (2004). Insights from Brain Research: A Brain-Friendly Approach to Teaching Management Accounting. MBAR Journal, 5(1),20-32.

Mackey, J., \& Hughes, V. (1993, May). Decision Focused Costing at Kenco, Management Accounting, 22-26.

Martichenko, R. (2004, November). Continuous Improvement: What's the Problem? Logistics Quarterly, $10(4)$.

Maull, R., Brown, P., \& Cliffe, R. (2001). Organisational culture and quality improvement. International Journal of Operations \& Production Management, 21(3), 302-326.

McManus, J. (1994). TQM - Lessons to Be Learned from Failure, Managing Service Quality, 4(6), 8-9.

McNair C. J., Mosconi, W., \& Norris, T. (1988). Meeting the Technology Challenge: Cost Accounting in a JIT Environment. National Association of Accountants, Montvale, 
Miller, P., \& O'Leary, T. (1987). Accounting and the construction of the governable person. Accounting, Organizations and Society, 12(3), 235-265.

Najmi, M., \& Kehoe, D.F. (2000). An integrated framework for post-ISO 9000 quality development. International Journal of Quality \& Reliability Management, 17(33), 226-258.

Ngowi, A.B. (2000). Impact of culture on the application of TQM in the construction industry in Botswana. International Journal of Quality \& Reliability Management, 17(4/5), 442-452.

Page, R., \& Curry, A. (2000). TQM - a holistic view. The International Bi-Monthly for Total Quality Management: The TQM Magazine, 12(1), 11-17.

Pool, S.W. (2000). The learning organization: Motivating employees by integrating TQM philosophy in a supportive organizational culture. Leadership \& Organization Development Journal, 21(8), 373378.

Prabhu, V., Appleby, A., Yarrow, D., \& Mitchell, E. (2000). The impact of ISO 9000 and TQM on best practice / performance. The International Bi-Monthly for Total Quality Management: The TQM Magazine, 12(2), 84-91.

Quattrone, P., \& Hopper, T. (2001). What does organizational change mean? Speculations on a taken for granted category. Management Accounting Research, 12, 403-435.

Ring, P. S., \& Van de Ven, A. 1994. Developing processes of cooperative Intel-organizational relationships. Academy of Management Review, 19, 90-118.

Samson, D. (1997). Progress in total quality management: Evidence from Australasia. International Journal of Quality Science, 2(4), 214-235.

Saravanamuthu, R. (1998). The Political Use of Management Accounting Information: "When I Choose a Word it Will Mean Neither More Nor Less.” (Humpty Dumpty), Osaka University, Japan, pp. 417-436

Schein, E. (1984). Coming to a new awareness of organizational culture. Sloan Management Review, Winter.

Schonberger, R. (1991). Performance measurement: the integration of time and customer. CAM-I Programme Meeting.

Schneider, S.K., \& Northcraft, G.B. (1999). Three social dilemmas of workforce diversity in organisations: A social identity perspective. Human Relations, 52(11), 1445.

Sinclair, J., \& Arthur, A. (1994). Inhospitable cultures and continuous improvement. International Journal of Contemporary Hospitality Management, 6(12), 30-36.

Stewart, R.E. (1992). Pluralizing our past: Foucault in accounting history. Accounting, Auditing \& Accountability Journal, 5(2), 57-73.

Strebel, P. (1996). Why do employees resist change? Harvard Business Review, pp. 86-92.

Sunder, S. (2002). Management Control, Expectations, Common Knowledge, and Culture. Journal of Management Accounting Research, Sarasota, 14, 173.

Taylor, F.W. (1911). The principles of scientific management. New York, London, Harper \& Brothers.

Terziovski, M., \& Samson, D. (2000). The effect of company size on the relationship between TQM strategy and organisational performance. The TQM Magazine, 122, 144-148.

The transfer of best practices: How to build a culture of benchmarking and continuous learning - part 2 . (2000b). Benchmarking: An International Journal, 72, 146-167.

Upton, D.M., \& Kim B. (1998). Alternative Methods of Learning and Process Improvement in Manufacturing. Journal of Operations Management, 16, 1-20

Voss, C. A., \& Blackman, K. (1996). Impact of national and parent country origin on world-class manufacturing: findings from Britain and Germany. International Journal of Operations Management, 16, 98-115.

Walsh, E.J., \& Stewart, R.E. (1993). Accounting and the construction of institutions: The case of a factory. Accounting, Organizations and Society, 18(7/8), 783-800.

Westrup, Hopper, \& Jazayeri. (2001). Free Beer Tomorrow: Idealised Accountability, World Class Manufacturing and Competitiveness (with C. Westrup \& M. Jazayeri). Working paper. 
Williams, A., Dobson, P., \& Walters, M. (1994). Changing Culture: New Organisational Approaches, 2nd edition. Institute of Personnel Management, Cromwell Press, Wiltshire, UK.

Willmott, H. (1998). Accounting for teamwork: A critical study of group-based systems of organisational control. Administrative Science Quarterly, 43, 358-396.

Whymark, J. (2000a). The transfer of best practices: How to build a culture of benchmarking and continuous learning - part 1. Benchmarking: An International Journal, 71, 62-78.

Zairi, Z., Letza, S.R., \& Oakland, J.S. (1994). Does TQM impact on bottom-line results? The TQM Magazine, 6(1), 38-43. 


\section{APPENDIX}

\section{EXHIBIT 1 \\ CHARACTERISTICS OF A CONTROL CULTURE}

1. "One best way" - practical standards

2. "Get the job done on budget and on time"

3. Budget based MBE analysis

4.Employee disempowerment

5. Built-in budget slack

6.Individual performance

7. Following the rules

8. Responsibility centers

\section{EXHIBIT 2 ACCOUNTING LITERATURE REQUIREMENTS FOR A CI-AIS}

1. Measurement of

- actual costs on materials, labor, and overhead expenses (Howell and Soucy 1987b)

- product profitability (Kaplan 1992)

2. Establishment of ideal, long-range standards -- Fleischman and Tyson 1996

3. Elimination of dysfunctional budgeting practices that limit improvement -- Hope and Fraser 2003

4. Compatibility with WCM

a. Schonberger 1991

- Problem-based management

- Focus on improving processes

- Accounting data to replace TQM in management of processes

b. Jazayeri and Hopper 1999

- Focus on actual costs and trends

- Continuous cost reduction within operations

- Assign overhead costs based upon time

5. Compatibility with JIT -- McNair et al. 1988

- Information to support manufacturing strategy

- Identification of non-value adding costs

- Accurate and timely cost driver information

- Accurate product costs

6. Design of customer-oriented performance measures -- Lakhe and Mohanty 1994

- To establish a criteria that allows cost/benefit tradeoffs over the entire value chain

- To reduce conflicts among different departments by unifying them into a common culture (Schneider and Northcraft 1999) 


\section{EXHIBIT 3 \\ EXAMPLES OF NON-ACCOUNTING CI IMPLEMENTATION TOOLS FOR WCM}

1. flexible processes and facilities

2. advanced information technologies

3. planning and control

4. product design and innovation

5. financial controls - use $\mathrm{ABC}$ to identify product and customer profitability, minimize variable costs

6. physical performance measures (nonfinancial)

7. organizational structures - shift from commanding to learning and facilitating

8. benchmarking to challenge current traditional practices, attitudes, and attainable goals

9. employee involvement - etc. change from confrontation to cooperative relationships, flat organizations

10. Total Quality Management

11. long-term strategic plans

12. statistical process control

\section{EXHIBIT 4 \\ THE CHANGE PROCESS}

\begin{tabular}{|c|c|c|}
\hline The Learning Process & The CI Process Loop & Business Culture Objective \\
\hline Waste Identification & $\begin{array}{l}\text { The AIS prioritizes wasteful } \\
\text { activities for sequential } \\
\text { investigation. }\end{array}$ & $\begin{array}{l}\text { Projects with the greatest waste can be } \\
\text { most easily justified for change. }\end{array}$ \\
\hline $\begin{array}{l}\text { Incremental } \\
\text { Solutions }\end{array}$ & $\begin{array}{l}\text { Root cause analysis for } \mathrm{CI} \text { is } \\
\text { limited to one activity at a } \\
\text { time. }\end{array}$ & $\begin{array}{l}\text { Focusing on one project at a time } \\
\text { limits the threat to employees and } \\
\text { makes learning easier. }\end{array}$ \\
\hline Validation & $\begin{array}{l}\text { The pre-existing norm of } \\
\text { profitability justifies the } \\
\text { improvements made to the } \\
\text { waste activity. }\end{array}$ & $\begin{array}{l}\text { The change in costs justify changing } \\
\text { existing normative procedures. }\end{array}$ \\
\hline Repetition & $\begin{array}{l}\text { The next most wasteful } \\
\text { activity is selected and the } \\
\text { process is repeated. }\end{array}$ & $\begin{array}{l}\text { Through repetition, employees learn } \\
\text { the implications of sharing ideas and } \\
\text { collaboration, enhancing the new } \\
\text { culture. }\end{array}$ \\
\hline
\end{tabular}




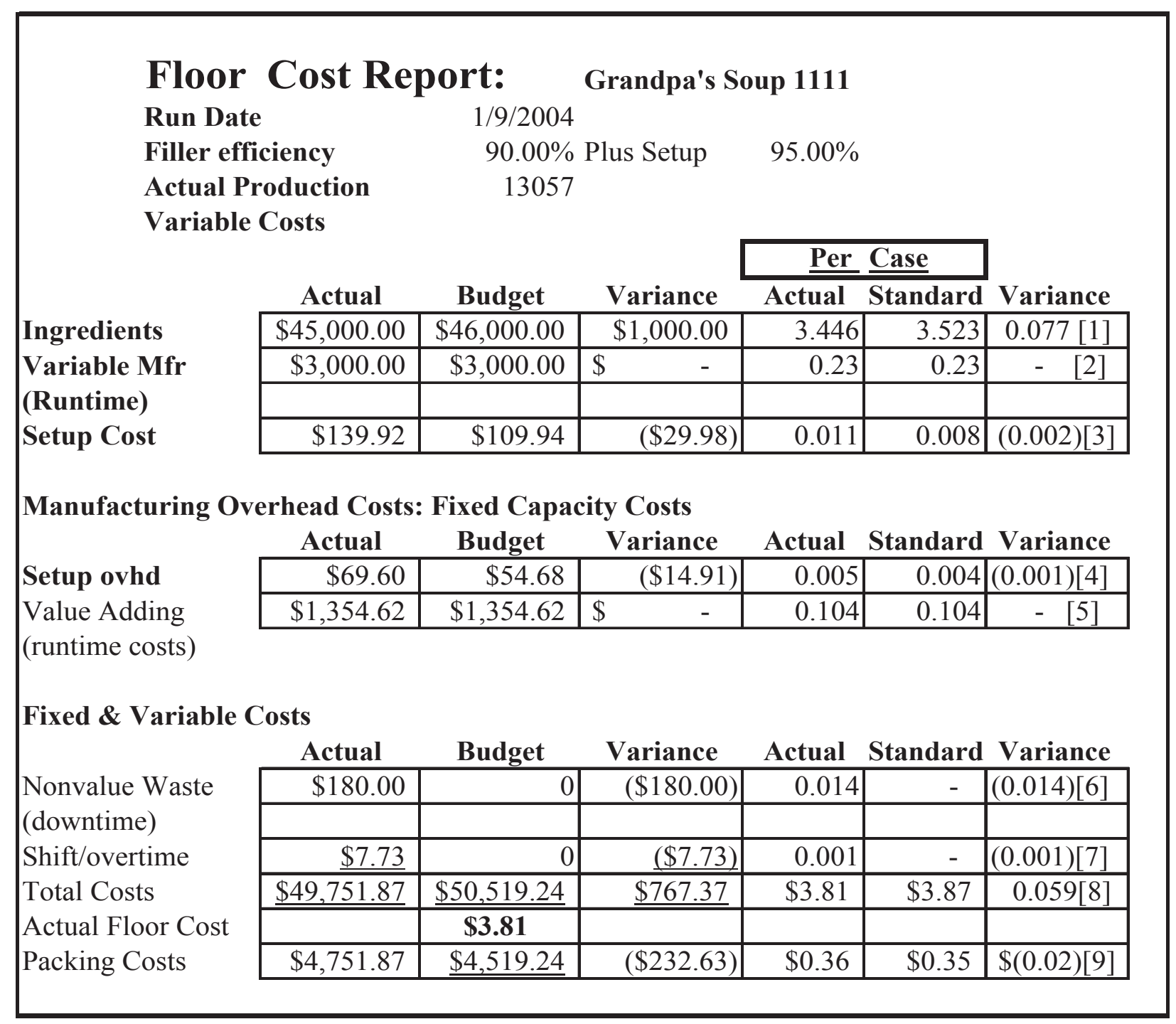

[1] This row presents the actual, standard, and variances for ingredients in total and per case.

[2] This row assigns variable runtime costs using perfect production and standards. Thus there are no variances.

[3] This is the setup variance based upon estimated historical perfect standards. Thus actual, budget and variances in total and per case are available.

[4] These are the fixed setup costs with the same treatment as the variable setup costs.

[5] These are the fixed variable runtime costs with the same treatment as the variable runtime costs.

[6] This is the waste calculated by the excess time used over perfect standards. It includes a fixed and variable portion.

[7] This is a special calculation used to deal with shift differentials due to evening or day shifts.

[8] This is the total production costs including all variances.

[9] This is the total packing costs and does not include ingredient costs. This is an important figure for strategic decisions and was requested by management. 
EXHIBIT 6

MONTHLY CONTINUOUS IMPROVEMENT REPORT

Line Floor Cost Report

1 LTR: RANKED BY TOTAL VARIANCE PER CASE

\begin{tabular}{|c|l|c|c|c|cc|c|c|}
\hline \multirow{2}{*}{ Item\# } & \multirow{2}{*}{ Product Name } & \multirow{2}{*}{ Date } & \multicolumn{2}{|c|}{ Efficiency } & Total Cost & Ingredients & Packing \\
\cline { 5 - 9 } & & & Run & Units & var/case & var/case & var/case \\
\hline 1201 & Papa's Soda & 29-Apr & $22 \%$ & 769 & $\$$ & $(1.73)$ & $(\$ 0.72)$ & $(\$ 1.01)$ \\
\hline 1550 & Papa's SF & 13-Jun & $23 \%$ & 212 & $\$$ & $(1.66)$ & $(\$ 1.32)$ & $(\$ 0.35)$ \\
\hline 1566 & Papa's Gravey Style & 3-Jun & $46 \%$ & 923 & $\$$ & $(1.22)$ & $(\$ 0.91)$ & $(\$ 0.31)$ \\
\hline 7600 & Blueberry Gravey & 9-May & $76 \%$ & 2533 & $\$$ & $(0.05)$ & $(\$ 0.02)$ & $(\$ 0.04)$ \\
\hline 6803 & Grandma Ale & $10-A p r$ & $83 \%$ & 3961 & $\$$ & $(0.03)$ & $(\$ 0.01)$ & $(\$ 0.03)$ \\
\hline 5515 & Sparkling Creek Water & $16-\mathrm{Apr}$ & $67 \%$ & 400 & $\$$ & $(0.01)$ & $\$ 0.00$ & $(\$ 0.01)$ \\
\hline
\end{tabular}




\section{EXHIBIT 7 \\ INNOVATIVE ACTION RESEARCH - DESIGNING MCSS TO SUPPORT CI EMPLOYMENT CONTRACTS}

\begin{tabular}{|c|c|c|}
\hline Theory & Problem/Issue & Design Feature Solution \\
\hline $\begin{array}{c}\text { Norms of } \\
\text { Behavior } \\
\text { Business culture } \\
\text { defines "the way } \\
\text { we do things } \\
\text { around here" }\end{array}$ & Cultural resistance to change. & $\begin{array}{c}\text { Efficiency for learning } \\
\text { new cultural norms of behavior }\end{array}$ \\
\hline \multirow{3}{*}{$\begin{array}{l}\text { Information } \\
\text { Economics } \\
\text { (productivity } \\
\text { exp ansion } \\
\text { decisions } \\
\text { using 'drift') }\end{array}$} & $\begin{array}{l}\text { Guide efficient change } \\
\text { when optimal solution is not known }\end{array}$ & Timely feedback to minimize loss \\
\hline & $\begin{array}{c}\text { Operational Correlation - } \\
\text { between accounting measures and company } \\
\text { value }\end{array}$ & $\begin{array}{l}\text { Accounting-based measures } \\
\text { of in-process improvement }\end{array}$ \\
\hline & $\begin{array}{c}\text { Strategic Correlation - } \\
\text { between accounting measures } \\
\text { and company value }\end{array}$ & $\begin{array}{l}\text { Project by project measures } \\
\text { of projected cashflows }\end{array}$ \\
\hline \multirow{7}{*}{$\begin{array}{l}\text { Agency } \\
\text { Theory }\end{array}$} & $\begin{array}{l}\text { Efficient employment contracting } \\
\text { (Risk and Trust) }\end{array}$ & $\begin{array}{l}\text { Accounting based employment contracts } \\
\text { provide boundaries for rational decisions. }\end{array}$ \\
\hline & Increasing Organizational Trust & $\begin{array}{c}\text { Rep eated operational exchanges } \\
\text { using formal structures to develop trust } \\
\text { by learning new outcomes }\end{array}$ \\
\hline & $\begin{array}{c}\text { Risk - } \\
\text { Uncertainty about new outcomes }\end{array}$ & $\begin{array}{c}\text { Reduce uncertainty } \\
\text { with informative timely feedback }\end{array}$ \\
\hline & $\begin{array}{l}\text { Risk - } \\
\text { Potential Economic Loss from new outcomes }\end{array}$ & $\begin{array}{l}\text { Make incremental changes } \\
\text { to limit potential loss }\end{array}$ \\
\hline & \multirow{3}{*}{$\begin{array}{c}\text { Participation - } \\
\text { Moral hazard causes shirking }\end{array}$} & $\begin{array}{l}\text { AIS selects opportunities for CI to limit } \\
\text { shirking by defining productivity path }\end{array}$ \\
\hline & & $\begin{array}{c}\text { Perfect Standards - } \\
\text { limit shirking or negotiation of slack }\end{array}$ \\
\hline & & $\begin{array}{c}\text { Visible Actions - } \\
\text { limit shirking opp ortunities }\end{array}$ \\
\hline \multirow{6}{*}{$\begin{array}{l}\text { Constructive } \\
\text { Learning } \\
\text { Theory }\end{array}$} & $\begin{array}{l}\text { Manage CI: } \\
\text { Efficient learning }\end{array}$ & $\begin{array}{l}\text { Design an MCS including Constructive } \\
\text { Learning theory for easy learning }\end{array}$ \\
\hline & $\begin{array}{l}\text { Manage CI: } \\
\text { Efficient constructive learning path }\end{array}$ & $\begin{array}{c}\text { AIS selects productivity expansion projects } \\
\text { to guide sequentially learning } \\
\text { project by project }\end{array}$ \\
\hline & $\begin{array}{c}\text { Manage CI: } \\
\text { Hidden information, shirking, risk }\end{array}$ & $\begin{array}{c}\text { Work team Collaboration, } \\
\text { Sharing information, } \\
\text { and risk group validation }\end{array}$ \\
\hline & $\begin{array}{l}\text { Learn new CI culture: } \\
\text { Complex new ideas }\end{array}$ & $\begin{array}{l}\text { Minimal incremental change build on pre- } \\
\text { existing norms of conduct (knowledge } \\
\text { about 'the way to do things' plus new ideas) }\end{array}$ \\
\hline & $\begin{array}{l}\text { Learn New CI Culture: } \\
\text { Learning } \\
\end{array}$ & $\begin{array}{l}\text { Repetitive in-process budgeting cy cle } \\
\text { allows learning CI outcomes } \\
\end{array}$ \\
\hline & $\begin{array}{l}\text { Learn New CI Culture: } \\
\text { Resistance to change }\end{array}$ & $\begin{array}{l}\text { Use pre-existing norm of profitability } \\
\text { to validate "new way to do things" }\end{array}$ \\
\hline
\end{tabular}

